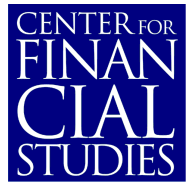

No. $2001 / 09$

Core Inflation in the Euro Area: Evidence from the Structural VAR Approach

Elke Hahn

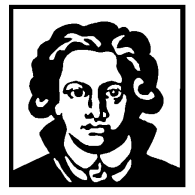




\title{
Core Inflation in the Euro Area: Evidence from the Structural VAR Approach
}

\author{
Elke Hahn*
}

This version: April 2002

\begin{abstract}
:
Against the difficult background of analyzing aggregated data in this paper core inflation in the euro area is estimated by means of the structural vector autoregressive approach. We demonstrate that the HICP sometimes seems to be a misleading indicator for monetary policy in the euro area. We furthermore compare our core inflation measure to the wide-spread "ex food and energy" measure, often referred to by the ECB. In addition we provide evidence that our measure is a coincident indicator of HICP inflation. Assessing the robustness of our core inflation measure we carefully conclude that it seems to be quite reliable.
\end{abstract}

JEL Classification: C32, E31

Keywords: Core Inflation, Structural VAR Approach, Euro Area

- Center for Financial Studies at the Johann Wolfgang Goethe-Universität, Taunusanlage 6, D-60329 Frankfurt/Main, Germany. Phone: +49-69-24 2941 12, Fax: +49-69-24 2941 77, Email: hahn@ifk-cfs.de.

The author thanks Axel A. Weber, Dieter Nautz, Christian Müller and an anonymous referee for many helpful comments. Of course, all remaining mistakes are mine. 


\section{Introduction}

Medium-term orientation of monetary policy implies that a central bank concerned with the maintenance of price stability should not react on transitory price movements but focus its monetary policy on the price trend. Therefore, independently of what monetary policy strategy is pursued, exact information about the price trend is essential for a central bank. However, it is not possible to raise data on the price trend. In practice, inflation is often measured in terms of the development of a price index. Usually a consumer price index (CPI) is applied, since the value of money is in general associated with the purchasing power of money on the consumer level. However, this wide-spread method of measuring inflation contains serious problems for monetary policy. Since the CPI is not designed to measure the price trend, it often delivers a distorted picture of underlying inflation.

The conceptual mismatch between underlying inflation and CPI inflation is best illustrated by the theoretical definition of inflation. In theory inflation is defined as a sustained increase in the general price level. According to this definition only a persistent increase of the price index corresponds to the term inflation, while temporary increases of the CPI do not fulfill the criteria of inflation. The focus of the definition on the general price level adds two further problems of CPI price measurement. Firstly, the CPI is based on a representative choice of consumer goods and therefore comprises only the price developments of selected consumer goods and by far not the price developments of all goods in the economy. Secondly, volatile price developments of individual goods often deliver a distorting impact on the CPI not in line with the concept of inflation.

In view of the deficiencies of the CPI in capturing underlying inflation, in the literature a huge number of different measures of underlying inflation, known as core inflation measures, have been proposed. No consensus is achieved yet on which measure performs best. While no unique definition of core inflation exists, core inflation is usually defined in terms of the method it is constructed with. The variety of core inflation approaches can be divided into three main categories according to the information set they rely on. These are methods based on the cross sectional distribution of prices, panel methods, and 
time series methods.

The cross sectional approaches to core inflation address the problem of distortion in CPI inflation by reweighing the impact of the individual price data of the price index. Different cross sectional measures are distinguished by the kind of reweighing that is applied. Important approaches of this category are the exclusion measures like e.g. the well known "ex food and energy" approach, the limited influence estimators proposed by Bryan $\& 5$ Cecchetti (1994) and Bryan, Cecchetti \& WigginsII (1997) and the Edgeworth or variance weighted index suggested by Diewert (1995) and Dow (1994).

The panel methods combine information on the cross sectional and the time series dimension of individual price changes to identify core inflation. A major approach based on panel data is the dynamic factor index developed by Stock $\&$ Watson (1991) measuring core inflation as the the common element of the individual price changes.

Among the time series approaches univariate measures are distinguished from multivariate methods. The univariate measures rely solely on information of the aggregated price index. Different smoothing techniques are applied. These comprise simple methods like taking moving averages as well as more sophisticated methods like the Hodrick Prescott filter and the Kalman filter. Against that, the multivariate approaches next to the price index take into account additional information in terms of further economic variables. They basically comprise the structural vector autoregression (VAR) approach suggested to the measurement of core inflation by Quah $\&$ Vahey (1995) and the common trends approach proposed by Blix (1997). Modelling important economic interactions between the variables considered in terms of (long-run) restrictions, a measure of core inflation based on economic theory is obtained. This economic foundation essentially sets the multivariate time series approaches apart from all other measures of core inflation. Thereby an important contribution to diminishing the mismatch between the theoretical definition and the practical measurement of inflation is put forward.

Next to their basic purpose of depicting underlying inflation core inflation measures may serve additional purposes within the analysis of price developments (see European Central Bank (2001)). They may be used to identify the kind of shocks that affect CPI 
inflation. Furthermore, representing the persistent component of inflation, they might serve as leading indicators of CPI inflation.

In this paper a measure of core inflation for the euro area is presented. The European Central Bank (ECB) has defined its primary objective, price stability in the euro area, in terms of an increase of the Harmonised Index of Consumer Prices (HICP) below two percent over the medium term. With the medium term orientation the ECB has made clear that it does not respond to temporary developments of the HICP, but focuses its monetary policy on the price trend. In view of the challenge to distinguish between temporary and persistent movements of the HICP, core inflation measures could be a valuable guideline within the second pillar of the two pillar strategy of the ECB.

Core inflation in the euro area in this paper is measured by means of the structural VAR approach. To our best knowledge, so far only Wehinger (2000) has applied this approach to core inflation measurement in the euro area. ${ }^{1}$ The main goal of this paper is to assess the price trend in the euro area. In addition we compare our measure of core inflation to the wide-spread "ex food and energy" inflation measure, which is applied by the ECB to the analysis of price developments in the euro area. We furthermore assess the ability of our core inflation measure to track future HICP inflation and deliver some insight into the robustness of our core inflation measure with respect to new observations, which is a major criticism concerning structural VAR core inflation measurement. Our analysis is the first of its kind that also provides some evidence for the time period after the start of the European Monetary Union (EMU). Putting a strong emphasis on the transparency of the data we present a detailed account of our data sources and aggregation methods, which is not yet common in the existing literature.

The rest of the paper is organized as follows. In chapter 2 the structural VAR approach and the identification restrictions underlying the empirical work are explained. In chapter 3 special problems concerning the aggregated euro area data, the data used and their properties are discussed. Chapter 4 presents the empirical results. The specification of the VAR model is derived. Impulse responses and variance decompositions are analyzed.

\footnotetext{
${ }^{1}$ Fase 8 Folkertsma (1997) based their analysis on a different group of countries. They used the structural VAR approach to estimate core inflation in the European Union.
} 
Historical decompositions deliver an insight into inflation dynamics in the euro area. Core inflation in the euro area is compared to HICP inflation as well as to "ex food and energy" inflation. In this chapter we furthermore analyze the ability of our core inflation measure to track future HICP inflation and assess its robustness with respect to new observations. Chapter 5 summarizes and evaluates important empirical results.

\section{The Structural VAR Approach to Estimating Core Inflation}

In this chapter first the basic idea underlying the structural VAR estimation of core inflation is delivered. Furthermore a short formal representation of the structural VAR approach is given. Thereafter the identification restriction is introduced.

\subsection{The Idea}

In the seminal paper on estimating core inflation using the structural VAR approach Quah $\&$ Vahey (1995) proposed a technique of measuring core inflation based on an explicit longrun economic hypothesis. This hypothesis is implemented in the VAR representation by applying a long-run identification scheme that goes back to Shapiro \& Watson (1988) and Blanchard \& Quah (1989).

More specifically, Quah \& Vahey (1995) estimated a VAR system in the growth rates

of real output and inflation. In this bivariate VAR model they considered two types of exogenous shocks, that are assumed to be uncorrelated with each other at all leads and lags. These shocks are distinguished by their long-run impact on the level of real output. While the one type of shocks is allowed to influence the level of real output in the long-run, the long-run impact of the other type of shocks on the level of real output is restricted to zero. Quah \& Vahey (1995) define the former as noncore inflationary shocks and the latter as core inflationary shocks. Since they had no strong prior about which types of shocks influence inflation in the long and short-run, they preferred to be agnostic on the exact interpretation of the shocks. In line with the specification of the shocks, core inflation 
in this model is defined as that component of measured inflation, that has no long-run impact on the level of real output.

This approach is consistent with the economic concept of the vertical long-run Phillips curve. According to this theory once wage contracts have been fixed, increases in core inflation can be benign for the real economy for some time but are neutral in the long run. However no consensus has yet been achieved on the speed of adjustment of the economy to core inflationary shocks. The Keynesian theory predicts a rather slow adjustment due to nominal rigidities in the adjustment process of the economy and hence a short-run trade-off between unemployment and inflation. According to the neoclassical theory such a short-run trade-off could only arise if the agents are subject to expectations errors. The adjustment speed to core inflation is then determined by the kind of underlying expectations process.

Against this theoretical background it shall be emphasized that the structural VAR approach does not restrict how quickly core inflationary shocks become output neutral. Rather, at shorter horizons the adjustment process of the economy is freely estimated and therefore according to Quah $\&$ Vahey (1995) delivers an assessment of the validity of the long-run identification restriction. Concerning to the concept of core inflation, in the long-run, measured inflation should not be determined by noncore inflationary shocks. Since no restriction of that kind is used, the estimated long run impact of noncore inflationary shocks on measured inflation serves as a further examination of the validity of the structural VAR core inflation framework.

As stressed by Wynne (1999) the concept of the vertical long-run Phillips curve is not without problems. The underlying assumption of the long-run neutrality of inflation with respect to the real economy implies that inflation has no long-run real costs. However, the presumption that these costs are substantial is the reason why central banks put their focus on the objective of price stability. A more realistic assessment proposed by Friedman (1977) might be a rather upward sloping, from left to right, long-run Phillips curve.

The proper specification of the VAR model depends strongly on the stochastic prop- 
erties of the data. In the literature inflation is frequently identified as $\mathrm{I}(1)$ variable as in Quah $\&$ Vahey (1995), but also quite often as I(0) process, leading to a different specification of the VAR model in terms of the price equation. ${ }^{2}$ While in the former case the price equation is defined in the first difference of inflation, the latter case implies a specification in the first difference of the price level. As a result the stochastic properties of the euro area data have to be checked before selecting the VAR model for the euro area.

Both model specifications basically are in line with the concept of the vertical longrun Phillips curve. The different results of the two specifications concerning inflation are attributable to their different impact on inflation expectations. ${ }^{3}$ In the case of I(1) inflation one of the two shocks (the core inflationary shock) exerts a permanent impact on core inflation. The permanent impact on inflation is induced by a change in inflation expectations represented by a shift in the short-run expectations augmented Phillips curve. This case therefore corresponds to the long-run neutrality of inflation and the long-run super-neutrality of the price level with respect to the real economy. Against that in the case of $\mathrm{I}(0)$ inflation inflation expectations are not affected by either of the two shocks implying an unchanged core inflation rate in the long run. In this framework both shocks affect prices permanently and inflation only temporarily. Core inflationary shocks should nevertheless be the utmost source explaining inflation over prolonged periods, yet dying out eventually. These effects potentially are in line with the stylized predictions of an AS-AD model for supply and demand shocks. As a result in this case identified shocks that exert a permanent impact on the level of output are classified as supply shocks and those that have no long-run effect on the level of output are defined as demand shocks. Compared to I(1) inflation the concept of I(0) inflation imposes only the weaker assumption of the long-run neutrality of the price level and is thus less controversial.

\footnotetext{
${ }^{2}$ See e.g. Aucremanne \&6 Wouters (1999), Bjornland (2000), Gartner \& Wehinger (1998) and Wehinger (2000).

3 Theses results are independent of the assumption concerning the expectations process (extrapolative, adaptive or rational expectations).
} 


\subsection{The Structural VAR Approach}

This section gives a short formal representation of the structural VAR approach. ${ }^{4}$ In the structural VAR representation (1) the vector $x_{t}=\left(x_{1}, x_{2}, \ldots, x_{n}\right)_{t}^{\prime}$, containing the variables under consideration, is a covariance stationary process with zero mean

$$
B(L) x_{t}=\epsilon_{t}
$$

where $\operatorname{Var}\left(\epsilon_{t}\right)=I$. The coefficient matrix $B(L) \equiv\left[B_{i j}(L)\right]$ is a polynomial in $L$ with $i, j=1,2, \ldots, n$, where $L$ indicates the lag operator. $B(L)$ is invertible. The structural shocks $\epsilon_{t}=\left(\epsilon_{1}, \epsilon_{2}, \ldots, \epsilon_{n}\right)_{t}^{\prime}$ are taken to be serially uncorrelated. They are assumed to be pairwise orthogonal and their variances are normalized to one. Their variance covariance matrix therefore equals the identity matrix $I$. Equation (2) shows the structural vector moving average (VMA) representation of $x_{t}$

$$
x_{t}=D(L) \epsilon_{t}
$$

where $D(L) \equiv\left[D_{i j}(L)\right]$ with $i, j=1,2, \ldots, n$ and $D(L)=B(L)^{-1}$.

To identify the coefficient matrices $D(L)$ and the structural shocks $\epsilon_{t}$ of the structural VMA representation, the reduced form of the VAR system with the reduced-form innovations $e_{t}=\left(e_{1}, e_{2}, \ldots, e_{n}\right)_{t}^{\prime}$ is estimated

$$
A(L) x_{t}=e_{t}
$$

where $A(L) \equiv\left[A_{i j}(L)\right]$ with $i, j=1,2, \ldots, n$ is invertible and $A(0)=I$. The variance covariance matrix of the reduced form innovations is given by $\Omega$, i.e. $\operatorname{Var}\left(e_{t}\right)=\Omega$. Inversion of $A(L)$ in equation (3) delivers the reduced-form Wold VMA representation (4) of $x_{t}$ :

$$
x_{t}=C(L) e_{t}
$$

Here the following relationships are satisfied: $C(L) \equiv\left[C_{i j}(L)\right]$ with $i, j=1,2, \ldots, n$, $C(L)=A(L)^{-1}$ and $C(0)=I$. It is assumed that the reduced form innovations are a linear combination (5) of the structural shocks

$$
e_{t}=S \epsilon_{t}
$$

\footnotetext{
${ }^{4}$ See e.g. Amisano \& Giannini (1997).
} 
where $S=D(0)=B(0)^{-1}$. Using equations (2),(4) and (5) a relationship (6) between the coefficient matrices of the reduced form VMA model and the structural VMA model is obtained:

$$
D(L)=C(L) S
$$

Estimation of the VAR model (3) and inversion of $A(L)$ delivers the coefficient matrix $C(L)$. If, furthermore, the matrix $S$ is known, complete identification of the structural model (2) is straightforward. From equations (5) and (6) the structural shocks and the coefficient matrices of the structural VMA representation (2) are obtained.

Identification of $S$ is achieved by the implementation of restrictions. In a system of dimension $n$ just-identification of the $n^{2}$ elements of $S$ requires $n^{2}$ restrictions. Multiplying each side of equation (5) by its transposed and taking expectations thereby considering that $\operatorname{Var}\left(\epsilon_{t}\right)=I$ and $\operatorname{Var}\left(e_{t}\right)=\Omega$ the following relationship (7) between the estimated variance covariance matrix $\Omega$ of the reduced form residuals and the matrix $S$ is obtained:

$$
\Omega=S S^{\prime}
$$

Since the variance covariance matrix $\Omega$ is symmetric, equation $(7)$ provides $n(n+1) / 2$ nonlinear restrictions on $S$. The missing $n(n-1) / 2$ restrictions are derived from economic theory. This kind of restrictions will be discussed in the next section for our bivariate model.

\subsection{Identification of the Shocks}

Anticipating the results on the stochastic properties of the euro area data (see section 3.4) the identification of the structural shocks refers to the VAR system in the first differences of the logs of output and the price index, i.e. $x_{t}=(\Delta y, \Delta p)_{t}^{\prime}$. In this bivariate VAR model just-identification of the four elements of the matrix $S$ requires four restrictions. In this case equation (7) provides three restrictions. The fourth is derived by economic theory. In line with Quah \& Vahey (1995) a long-run neutrality restriction, which can be interpreted as time-series equivalent to the vertical long-run Phillips curve, is applied. 
Hence the two structural shocks are distinguished with respect to their long-run impact on the level of real output.

Formally the long-run neutrality restriction is introduced in the following way. The matrix $D(1) \equiv \sum_{k=0}^{\infty} D(k)$ captures the long-run impact of the structural shocks $\epsilon_{t}=$ $\left(\epsilon^{S}, \epsilon^{D}\right)_{t}^{\prime}$ on the level of the endogenous variables, where $\epsilon_{t}^{S}$ denotes the supply shocks and

$\epsilon_{t}^{D}$ refers to the demand shocks. Therefore the long-run output neutrality restriction of the demand shocks is given by equation (8)

$$
D(1)_{12}=\sum_{k=0}^{\infty} D_{12}(k)=C_{11}(1) S_{12}+C_{12}(1) S_{22}=0
$$

where $C(1) \equiv \sum_{k=0}^{\infty} C(k)$.

Having completely identified the structural model, the structural VAR measure of core inflation is derived from the structural VMA representation of the measured inflation rate (9). CPI inflation is determined by the structural supply and demand shocks. Since the structural VAR approach defines core inflation as that component of measured inflation that has no long-run impact on the level of real output, core inflation is given by the second term on the right-hand side of equation (9).

$$
\Delta p_{t}=\sum_{k=0}^{\infty} D_{21}(k) \epsilon_{t-k}^{S}+\sum_{k=0}^{\infty} D_{22}(k) \epsilon_{t-k}^{D}
$$

\section{The Data}

In this chapter first special problems concerning the data of the euro area are discussed. Thereafter the choice of variables is illustrated and the sources of the euro area data as well as the applied aggregation methods are presented. An analysis of the data properties closes this chapter.

\subsection{Special Problems Concerning Euro Area Data}

Since the EMU started just three years ago, no long time series for it exist. A common solution to this problem is to construct artificial historical data for the euro area by aggregating the national data of the participating countries for the time prior to the 
EMU. Hereby problems concerning the quality of the data as well as the question of the appropriate aggregation method arise.

The quality of the data is influenced by different factors. Firstly, since the EMU comprises also countries for which no extensive statistical data are available, a certain amount of estimation, especially for earlier years, is unavoidable. Secondly, distortions are a major problem of euro area data. Additional to the usual distortions in national data euro area data are distorted due to non-harmonized national data since for (most of) the time prior to the EMU harmonized data are not available. Non-harmonization basically refers to different national data definitions. However concerning the GDP data non-harmonization additionally covers the problem of seasonal adjustment. Since not all participating countries provided original, non-seasonally adjusted, data different procedures of seasonal adjustment are applied to the national data.

A further critical issue in constructing historical euro area data is the choice of the appropriate aggregation method. Due to past exchange rate fluctuations simple aggregation across national data is misleading. Four main aggregation methods are in common use to meet this problem. Aggregation based on levels data or on growth rates, combined with either fixed or variable weights (see Beyer, Doornik $\&$ Hendry (2000)). Since we decided to use Eurostat data for the time horizons where these are available paying attention to consistency in aggregating our series we followed the aggregation method applied by Eurostat. We will refer to this issue in more detail in section 3.3.

\subsection{The Choice of Variables}

Our bivariate structural VAR model is based on the data of an output variable and of a price variable.

Possible candidates for the output variable are real Gross Domestic Product (GDP) and industrial production. From a monetary policy point of view a suitable measure of core inflation should be available timely. This issue is matched best by industrial production which is available monthly, while GDP has the substantial drawback of being measured only at quarterly frequency. However, the appeal of industrial production as 
a measure of output suffers heavily from the fact that it covers only a small fraction of output. ${ }^{5}$ Since GDP reflects output of the whole economy, a measure of core inflation referring to these data should be more reliable in capturing the trend of inflation as defined above. In view of aiming at depicting a less distorted picture of inflation dynamics than provided by the change in the CPI a strong preference is given to the choice of GDP as output variable.

The selection of the suitable price variable was more straightforward than that of the proper output variable yet not without compromise. The CPI as well as the GDP deflator seemed to be reasonable alternatives. Although the GDP deflator, contrary to the CPI, provides the preferred properties of firstly capturing the price movements of the whole economy and secondly only referring to domestic price movements the decision nevertheless went in favor of using the CPI, or more precisely, the HICP for the euro area. This decision reflects the fact that the analysis although intending to capture the "true" price trend nevertheless also aims at delivering a practicable measure of core inflation providing some benefit for the conduct of monetary policy. Since the ECB has defined its quantitative objective of price stability in terms of the HICP this time series had to be chosen. Using a different price indicator like the GDP deflator would not necessarily be a helpful tool for monetary policy aiming at keeping the HICP within its target range, since not even the trend increase of the other price measure has to match those of the HICP.

\subsection{The Data Sources and the Aggregation Procedure}

The official data of Eurostat on GDP and the HICP for the euro area do not cover time periods long enough for VAR analysis. ${ }^{6}$ Therefore the official euro area data had to be extended by own calculations based on national data of the participating countries. Yet even this horizon was determined by the availability of the national data. Going further

\footnotetext{
${ }^{5}$ In the year 2000 industrial production accounted for 23 percent of GDP in the euro area.

${ }^{6}$ Eurostat provides euro area GDP data from 1991(1) onwards, while the time series of the HICP for the euro area starts at 1995(1). A longer time series for the HICP starting at 1990(1) published by Eurostat in former days was not available due to data revision.
} 
back in history than 1984 did not seem reasonable, since the availability and quality of the GDP data deteriorated rapidly prior to that date. Hence the empirical work is based on quarterly data of the time period from 1984(1) to 2000(4).

The data source of real GDP in the euro area for the period from 1991(1) to 2000(4) is Eurostat. Since before 1991(1) no official GDP data for the euro area as a whole is available, for earlier dates national Eurostat data of the participating countries was used to compute euro area data. In periods where even no national Eurostat data was available estimations had to be carried out. If e.g. for these periods data from the Organization for Economic Cooperation and Development (OECD) was available, we calculated the level of the Eurostat data in the missing period using the growth rate of the OECD data. Following the aggregation method applied by Eurostat we transformed the national GDP series into ECU currency using the average exchange rates of the year 1995. Aggregating the national GDP series we obtained a GDP series for the euro area. The official Eurostat data then were linked to the aggregated data by applying the growth rates of the aggregated data to the level of the Eurostat data. All GDP data are seasonally adjusted data. ${ }^{7}$

Concerning to the price index HICP data as provided by Eurostat from 1995(1) onwards are used. For the time period prior to that date euro area CPI data are obtained relying on national CPI data of the euro countries taken from the OECD Main Economic Indicators. Although being aware of the deficiency that these are non harmonized CPI data, neither exactly referring to the same consumer goods basket nor applying the same weights, this is the only possibility to get euro area CPI time series long enough for VAR analysis. Weighting the national CPI data with their current share of euro area real GDP euro area CPI data are obtained. Visual inspection of the HICP and the aggregated CPI inflation time series indicated only slight deviations between the two series. We therefore conclude that combining the two series to a single inflation series seems reasonable. Again the data series were linked by applying the growth rates of the CPI data to the level of the HICP data. HICP as well as CPI data are constructed as end-of-quarter data. In

\footnotetext{
${ }^{7}$ An exact overview of the national GDP data sources and the time periods for which the data are estimated as well as the applied estimation technique is given in Table 6 in the Appendix B.
} 
the following we will refer to the combined series as HICP. Although we had to use seasonally adjusted GDP data we preferred not to seasonally adjust the HICP series. Since the ECB's definition for price stability refers to non-seasonally adjusted data exact comparability of the core inflation indicator with the ECB's interpretation of price stability necessitates the use of non-seasonally adjusted HICP data.

\subsection{The Data Properties}

As indicated above knowledge about the data properties is essential for the proper model selection. Therefore unit root and cointegration tests were performed to assess the stationary properties and cointegration features of the data. The results of the AugmentedDickey-Fuller (ADF) tests and the Phillips Perron (PP) tests summarized in Table 1 in Appendix A indicate, that GDP as well as the HICP are non-stationary (or more precisely $\mathrm{I}(1)) .{ }^{8}$ Visual inspection of the time series seems to support our conclusions (see Figure 6 in Appendix B). From the results achieved with the Johansen cointegration test, shown in Table 2 in appendix A we conclude that the two series do not follow a common trend.

\section{Empirical Results}

In this chapter the empirical results of the structural VAR model are presented and discussed. At first the VAR specification is introduced. Using impulse response functions and variance decompositions the properties of the identified structural shocks are analyzed. This analysis aims at checking whether the identified structural shocks are in line with their economic interpretation. Additionally it delivers an insight into the dynamic properties of the economy under consideration. The main part of this chapter is devoted to the presentation and discussion of core inflation in the euro area. A comparison is drawn between core inflation, HICP inflation and the wide-spread "ex food and energy" inflation measure. We furthermore analyze the leading indicator property of our core

\footnotetext{
${ }^{8}$ Calculations were performed with the software packages EViews3.0, Matlab5.3 and PcFiml9.10 (see Doornik \& Hendry (1998)).
} 
inflation measure and try to assess whether our measure is robust with respect to new observations.

\subsection{VAR Specification}

Referring to the results from the unit root and cointegration tests our VAR model is specified in the first differences of the logs of output and the price index. To determine the lag order of the VAR model several order selection criteria as well as Likelihood Ratio (LR) tests of parameter reduction were performed. While the Akaike Information Criterion (AIC) indicated four lags, the Hannan-Quinn (HQ) and the Schwarz Criterion (SC) reported two lags and the LR tests pointed towards a reduction from six to five lags yet not further (see Table 3 and Table 4 in the Appendix A). Analyzing a number of specification tests which indicated almost no serious misspecification in the $\operatorname{VAR}(5)$ representation we decided to rely on the LR test results (see Table 5 in the Appendix A). The VAR model therefore was estimated with a constant, seasonal dummies and five lags. Taking into consideration lags and differenced variables the estimation sample covers the time period from 1985(3) to 2000(4).

\subsection{Impulse Response Analysis}

The impulse response functions depicted in Figure 1 show the dynamic reactions of the level of real output and the HICP to an unanticipated, unique, one-unit supply and demand shock over a time period of ten years. ${ }^{9}$ The vertical axis refers to the log of the considered variable, while the horizontal axis indicates the time horizon in quarters.

The observed dynamic responses of the variables match the stylized predictions of an AS-AD model very well. A positive supply shock induces a permanent increase in the level of real output. In the euro area the effect stabilizes after about five years at its long-run level. Against that a positive demand shock temporarily increases real output. This short-run increase in output provides some evidence of a negatively sloped short-run

\footnotetext{
${ }^{9}$ The two standard error bands of the impulse response functions are obtained by Monte Carlo simulations based on normal random draws from the posterior distribution of the reduced-form VAR coefficients.
} 
Phillips curve. Euro area output reaches a peak after four quarters. Corresponding to the long-run restriction, the output effect vanishes after some time. In the euro area after about four years no significant output effect is present. The impulse response functions of the HICP depict the different impact of supply and demand shocks on prices. While a positive supply shock permanently reduces the HICP, a positive demand shock induces a permanent increase of the HICP. Corresponding to the shape of the impulse responses in the euro area it takes about five years until the HICP has reached its long-run level. In line with the stationarity property of inflation in the euro area, both shocks affect inflation only temporarily.
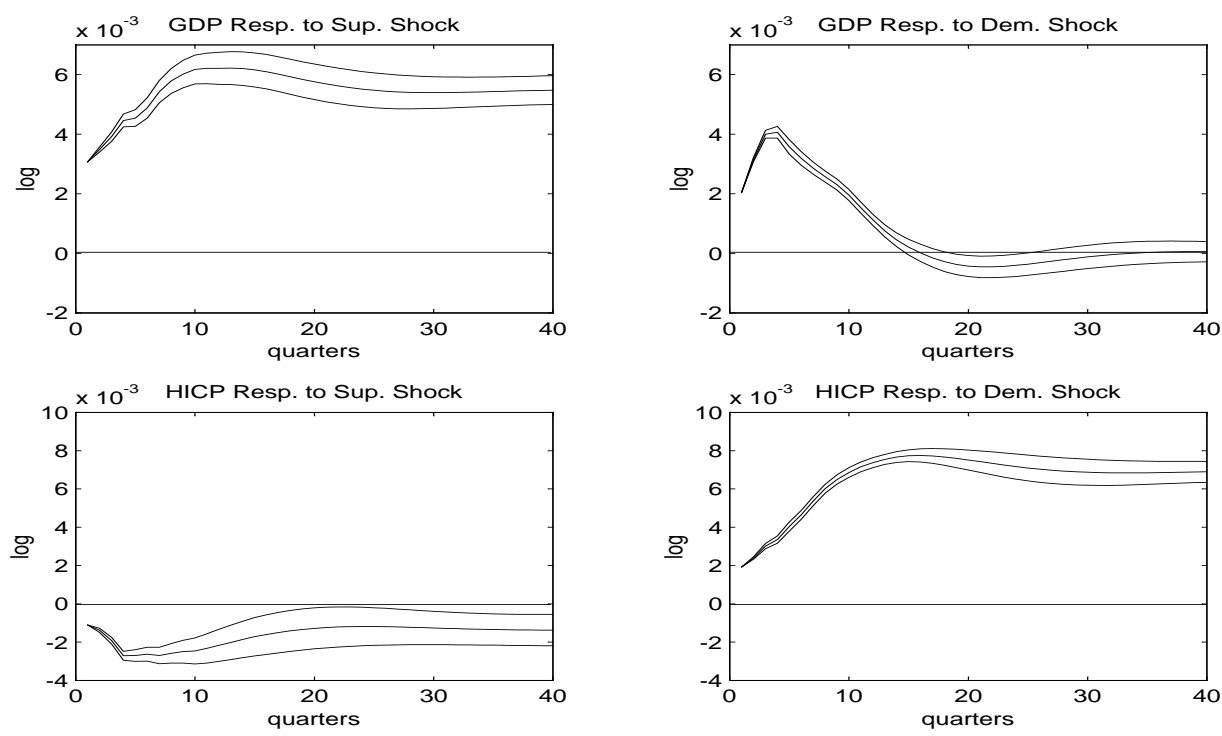

Figure 1: Impulse Responses

\subsection{Variance Decompositions}

The variance decompositions indicate the percentage contribution of the different structural shocks to the variance of the k-step ahead forecast errors of the variables. Hence, for each point in time the relative importance of the different structural shocks for the development of the variables can be assessed. Figure 2 shows the variance decompositions 
of the level of output and the HICP over ten years. The vertical axis indicates the contribution of the structural supply and demand shocks in percent, respectively, whereas the horizontal axis measures the time span in quarters.

The variance decomposition of output reveals that the variation in output in the euro area is attributable mainly to supply shocks. The long-run impact of the supply shocks on output approaches 100 percent, a result which is imposed by the identification procedure. Even in the short-run supply shocks account for more than half of the variance in output. The variance decomposition of the HICP indicates that in the euro area over all horizons demand shocks exert the major contribution to the variability in the HICP. In the shortrun demand shocks account for about 70 percent of the variance in the HICP. This share converges to 100 percent in longer horizons. It should be emphasized that this result is not due to any kind of imposed restriction. The results of the variance decomposition of the HICP are consistent with the concept of core inflation being demand driven. A demand driven measure captures the price trend, if demand factors account for the predominant part of the variation in the price index in the medium to long-run.
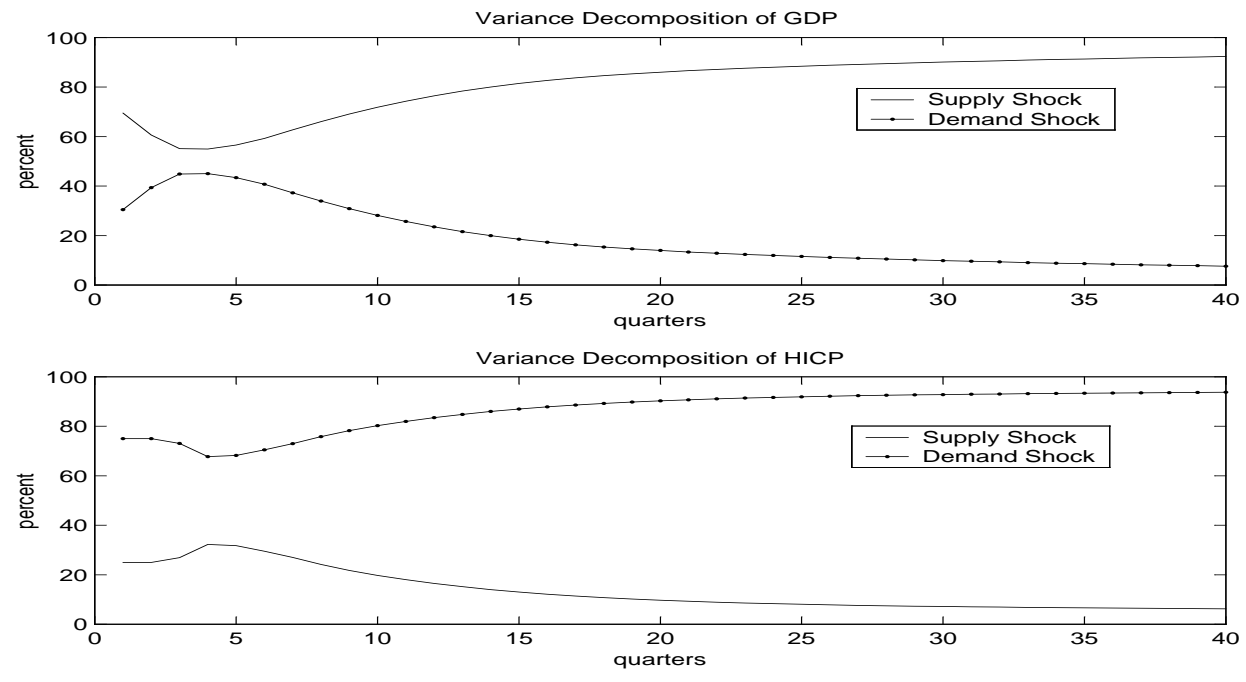

Figure 2: Variance Decompositions 


\subsection{Historical Decompositions: Estimated Core Inflation}

Historical decompositions are used to analyze the impact of individual structural shocks on the variables of the system. Thus the structural shock of interest enters the respective equation while the others are set to zero. The results of the impulse responses and variance decompositions indicate that the structural shocks of our model can be interpreted as supply and demand shocks. The calculation of core inflation by means of the structural demand shocks therefore seems to make sense economically.

Figure 3 depicts the (year-on-year) core inflation rate together with HICP inflation for the time period of $1990(1)$ to $2000(4)$. Furthermore noncore inflation capturing the impact of the supply shocks is shown. Drawing a comparison with other core inflation measures Figure 4 represents core inflation and HICP inflation together with the well known "ex food and energy" inflation ${ }^{10}$ for the time span of $1996(1)$ to $2000(4) .{ }^{11}$

Visual inspection of the Figures 3 and 4 shows that core inflation and HICP inflation follow the same "trend". This property is compelling, since only temporary (supply side) influences have been eliminated calculating core inflation. By construction the common development of the two inflation measures is determined by demand shocks, while deviations between core and HICP inflation are attributable to supply shocks. Furthermore the figures seem to suggest that the variability of core inflation is smaller than that of HICP inflation, as should be the case for a measure of the persistent component of inflation.

Regarding the development of core inflation in Figure 4 two different time periods have to be distinguished. Until 1999(2) core inflation basically was declining, while the time period thereafter was characterized by a strong increase in core inflation. The former period to a large degree comprises the time in the run-up to the EMU. In this period in many EMU countries large efforts have been made to bring down inflation and meet the Maastricht criteria. In the nineties the growth rates of the monetary aggregates in the euro area were brought down enormously. Likewise fiscal policy of the member countries in

\footnotetext{
${ }^{10}$ In this paper "ex food and energy" inflation is derived by excluding the prices of unprocessed food and energy. Basically the notion "ex food and energy" inflation has no unique meaning. A number of "ex food and energy" inflation measures are in common use which differ with respect to the categories of food and energy goods that are excluded from the index. An overview of "ex food and energy"-type measures calculated for the euro area is provided by Vega $\mathcal{E}$ Wynne (2001).

${ }^{11}$ This time span was determined by the availability of the HICP data.
} 


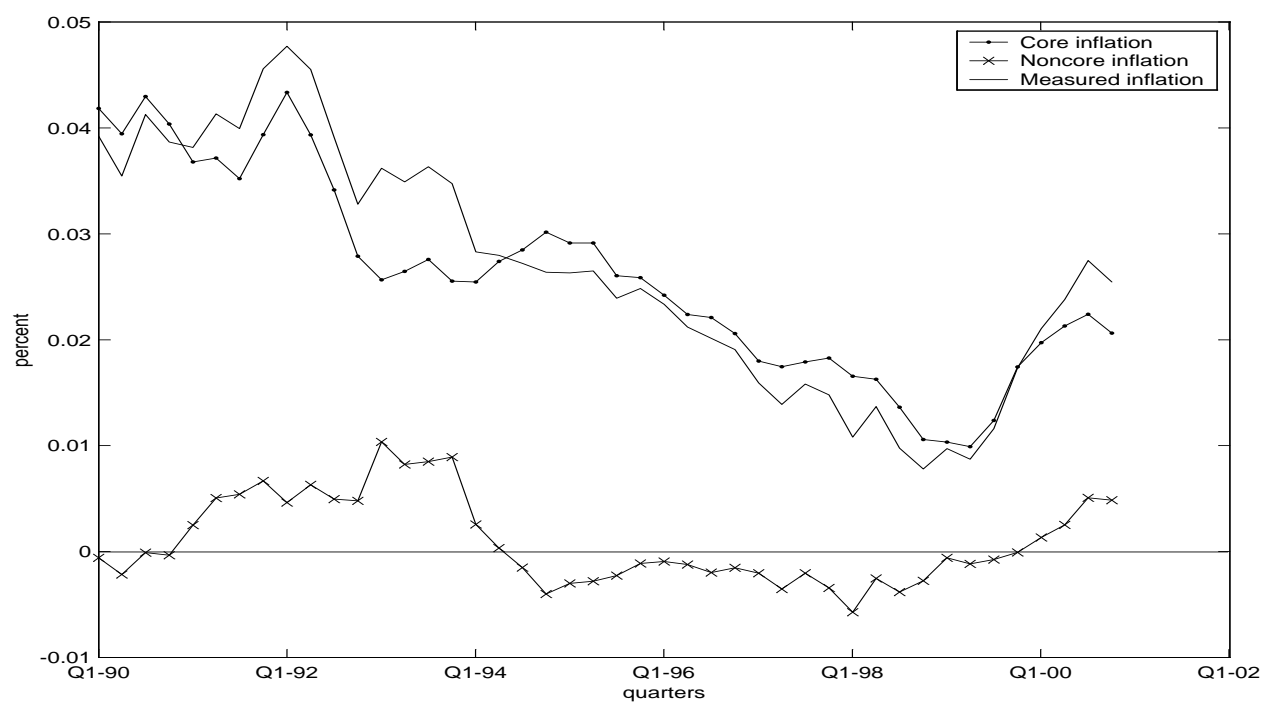

Figure 3: Core Inflation, Noncore Inflation and HICP Inflation

line with the Stability and Growth Pact followed a strict consolidation process. Moderate growth characterizing most of that time period may have further contributed to this development. One factor explaining the considerable increase in core inflation in the euro area since 1999(3) could be the strong growth dynamic of this time period. Furthermore, the marked depreciation of the Euro as well as the huge increase in oil prices may have partly spilled over into core inflation.

Next to the demand factors influencing the development of core inflation the supply factors responsible for the occasionally quite substantial deviations between core and HICP inflation are of interest. The time period under consideration basically covers two different periods of deviations between core and HICP inflation (see Figure 4). Between 1996(1) and 1999(4) HICP inflation underestimated core inflation, while in the time period thereafter the development was vice versa. In the first time span positive supply shocks have caused the understatement of core inflation by HICP inflation. The strong temporary decline in the oil prices may have fostered this development. After 1999(4) negative supply shocks have pushed HICP inflation above core inflation. This time a strong increase in oil 


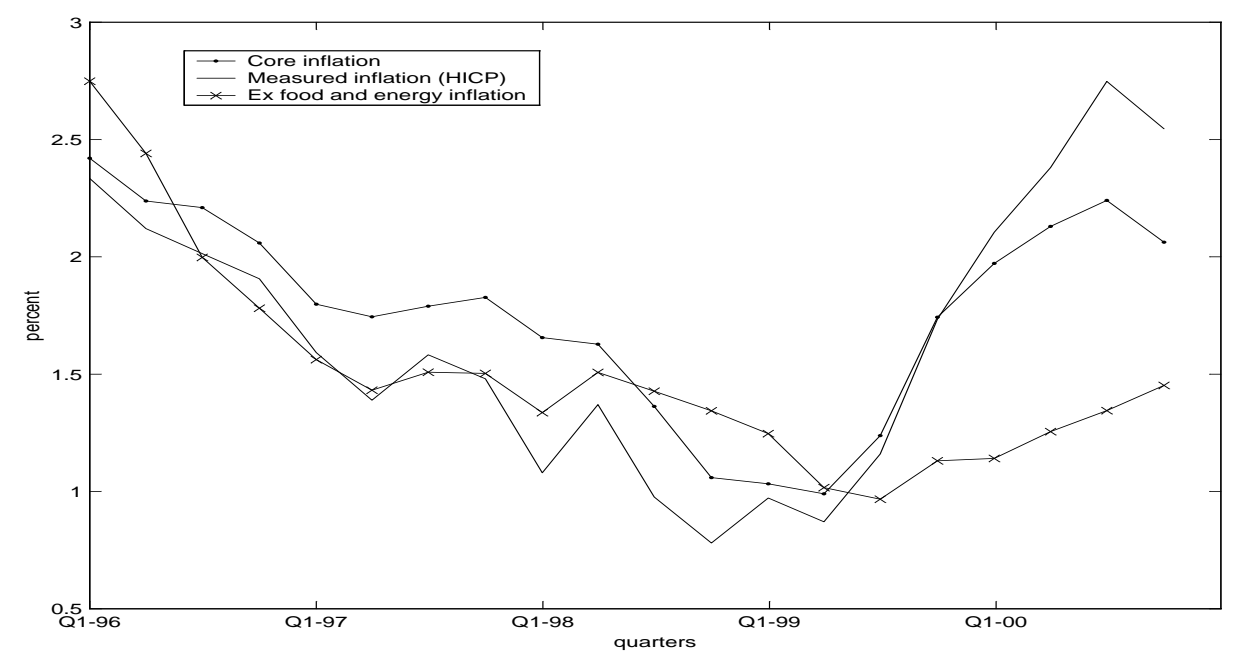

Figure 4: Core Inflation and "Ex Food and Energy" Inflation

prices as well as a pronounced rise in the prices of unprocessed food may have considerably contributed to this development.

In Figure 4 to a great extent core inflation and "ex food and energy" inflation deliver a quite similar assessment of underlying inflation. Only for the time period after 1999(2) a rather different picture emerges. Both measures basically indicate the same direction of the development of underlying inflation. Furthermore the slope of underlying inflation, except for the last time period, is indicated similarly. The time periods of over- or underestimation of underlying inflation reported by the two measures match each other quite well. However, the size of over- or underestimation sometimes differs substantially.

The strong congruence of time periods of under- and overestimation of underlying inflation is an indication, that those supply shocks considered by "ex food and energy" inflation exert an important influence on HICP inflation at the time period under consideration. The different size of under- or overestimation reported by the two measures is due to the fact, that core inflation other than "ex food and energy" inflation behaves very flexible with respect to the amount of a supply shock as well as the kinds of supply shocks that are considered. Complete elimination of special supply shocks as suggested 
by "ex food and energy" inflation is critical. If these shocks convey information about the price trend they should not be excluded (completely). Furthermore other supply shocks distorting the picture of the price trend should be eliminated from HICP inflation. Some of these factors seem to have played a major role between 1999(2) and 2000(4), where core inflation indicates a much stronger increase in the price trend and a much less pronounced influence of supply shocks than "ex food and energy" inflation.

As noted at the beginning a further desirable feature of core inflation measures is the ability to track future HICP inflation. We assess this property by looking at the measures ability to predict changes in HICP inflation. The Figures 3 and 4 indicate two major turning points in HICP inflation in 1992(1) and 1999(2). As can be seen core inflation changed the direction of its development at the same time as HICP inflation. It therefore tends to be a coincident indicator rather than a leading indicator of the reversal in HICP inflation. As will be shown in the next section this feature is robust with respect to new observations. "Ex food and energy" inflation performed worse than our core inflation measure. Figure 4 shows that "ex food and energy" inflation was still declining when HICP inflation already started to increase markedly in 1999(2). It therefore has to be considered a lagging indicator of HICP inflation. This feature was also reported by the European Central Bank (2001) not only for various "ex food and energy"-type inflation measures, but also for different trimmed mean measures as well as the Edgeworth measure.

\subsection{Robustness of the Results}

One of the major criticisms concerning time series based core inflation measures is that the history of the measure may change significantly each time new data are released. Since this is a serious objection making the measure more or less worthless for the practical purposes of monetary policy we tried to investigate this issue for core inflation in the euro area. $^{12}$

To assess the robustness of our core inflation measure with respect to new observations,

\footnotetext{
12 We furthermore checked the robustness of the core inflation indicator with regard to changes in the lag length of the VAR model. We found out that different specifications of the lag length that are considered as acceptable in terms of the misspecification tests lead to only very minor changes in the core inflation indicator.
} 
we estimated core inflation recursively over different time horizons. We decided to use the data sample from 1985(3) to 1998(1) as the starting point of recursive estimation. Starting with a shorter data sample did not seem reasonable, due to our limited data set. The results are depicted in Figure 5. To better assess the size of the changes we added a "tolerance" band of 0.3 percentage points hight around the mean of core inflation in each point in time, which is indicated by the lines with dots in Figure $5{ }^{13}$

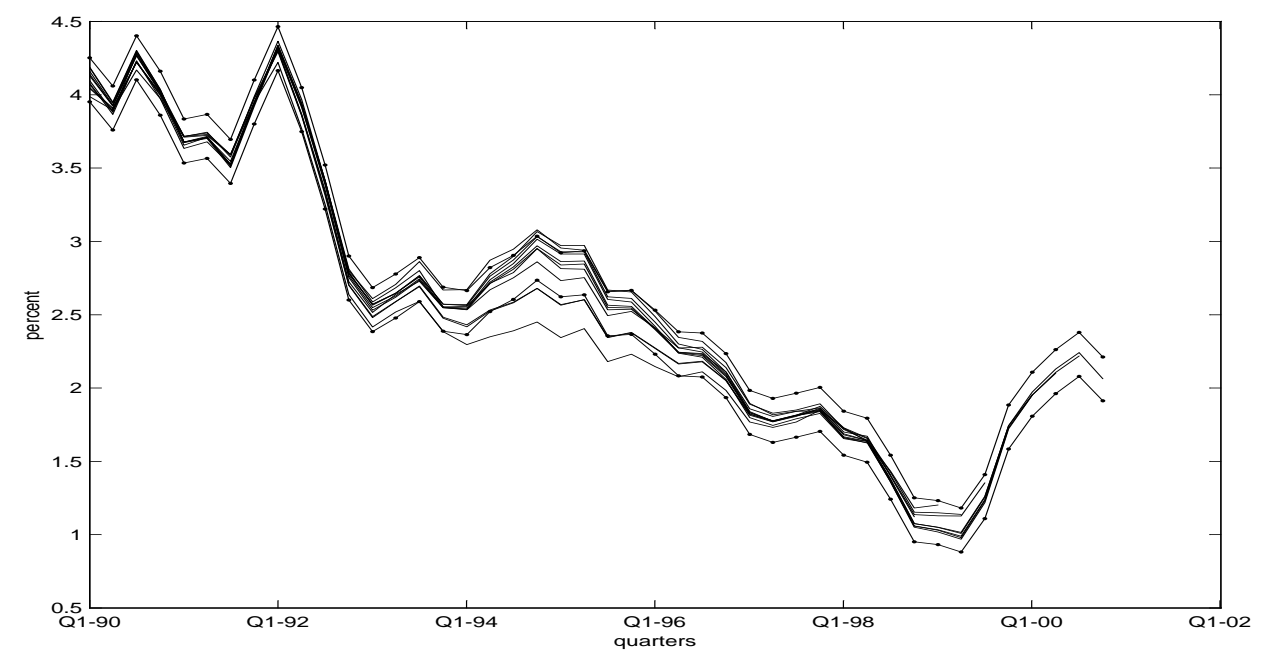

Figure 5: Robustness of the Results

From Figure 5 we conclude that most of the time our core inflation measure performs strikingly well. The results show that there are some changes in the historical level of core inflation with respect to new observations. However for most of the time reestimating over a period of three years these changes seem to be rather small. Only for a limited time period between 1994 and 1996 the changes are somewhat larger than the "tolerance" bands. One possible reason for the enhanced variability during that time period could be the change from non-harmonized to harmonized CPI data covered by that period. At the time period thereafter (until 1998) the variability seems to decrease. The time period after 1998 is not (completely) comparable since the number of data points declines due

\footnotetext{
${ }^{13}$ Of course the number of 0.3 percentage points is chosen somewhat arbitrarily.
} 
to recursive estimation. A further remarkable result is that the direction of core inflation movement never changed due to reestimation. In this respect our core inflation measure seems to be extremely robust. All in all the results seem to be quite promising. Of course due to the limited data sample our analysis can only deliver a first insight into the reliability of our core inflation measure.

\section{Conclusions}

Against the difficult background of analyzing aggregated time series data we estimated core inflation in the euro area by applying the structural VAR approach. This approach has the favorable property of relying on economic theory thereby diminishing the mismatch between the theoretical concept of inflation and the practical inflation measurement. From our results we conclude that the HICP sometimes seems to be a misleading inflation indicator for monetary policy in the euro area. Our measure of core inflation indicates a lasting decline in underlying inflation in the euro area over the nineties which is followed by a pronounced increase in inflation dynamics since the middle of the year 1999. Though HICP inflation basically followed a similar inflation pattern for some time periods quite substantial deviations between core and HICP inflation have been identified. Between 1996 and 1999 HICP inflation tends to underestimate the price trend, while in the period thereafter the development was vice versa.

The historical results seem to be quite robust against new observations. For most of the time period under consideration the size of revision in the level of core inflation broadly behaved within an limited range. Moreover the direction of core inflation movement was

never revised. Therefore finding our core inflation measure to be a coincident indicator of the reversal in HICP inflation seems to be a quite robust result. All in all the results seem to be quite promising. However, due to the limited data sample our analysis can only deliver a first insight into the reliability of our core inflation measure. The level of core inflation therefore has to be interpreted with some caution. Our results however deliver a general idea of how big these changes most likely are supposed to be.

While our bivariate structural VAR model provides some evidence concerning the im- 
pact of demand and supply factors on HICP inflation, it does not deliver any information on the kind of demand and supply factors. To analyze the kind of demand and supply factors, we therefore included further economic information in terms of the development of individual price series or those of other economic variables. A deeper insight can also be reached by comparing the results to those of other core inflation measures as we did by including the wide-spread "ex food and energy" inflation measure. Basically the determinants of inflation and core inflation could also be identified more deeply within a larger VAR model. However for the euro area we did not succeed in significantly identifying a broader set of structural shocks. In view of the problems concerning the euro area data and the resulting uncertainties surrounding them this result perhaps should not be too surprising. It rather illustrates the uncertainty the ECB has to build its analysis and decisions on.

To sum up, for each central bank concerned with the maintenance of price stability correct information about the price trend is essential however difficult to obtain. For the ECB acting in an environment of uncertainty correctly assessing the price trend is even harder. To get an extensive assessment of the price developments in the euro area the ECB should therefore take into account all possible sources of price information. Hereby core inflation measures could provide a valuable guideline in distinguishing between temporary and persistent price developments. Since a single best measure of core inflation does not exist, it is advisable to look at different core inflation measures, keeping in mind their respective advantages and drawbacks. 


\section{References}

Amisano, G. \& Giannini, C. (1997). Topics in Structural VAR Econometrics, second edn, Springer, Berlin, Heidelberg, New York.

Aucremanne, L. \& Wouters, R. (1999). A Structural VAR Approach to Core Inflation and its Relevance for Monetary Policy, in BIS (ed.), Measures of Underlying Inflation and their Role in the Conduct of Monetary Policy, Proceedings of the Workshop of Central Bank Model Builders, February 1999, Amsterdam.

Beyer, A., Doornik, J. A. \& Hendry, D. F. (2000). Reconstructing Aggregate Euro-zone Data, Journal of Common Market Studies 38(4): 613 - 24.

Bjornland, H. (2000). Identifying Domestic and Imported Core Inflation, Working Paper 00/4, International Monetary Fund.

Blanchard, O. \& Quah, D. (1989). The Dynamic Effects of Aggregate Demand and Supply Disturbances, American Economic Review 79(September): 655 - 673.

Blix, M. (1997). Underlying Inflation - A Common Trends Approach, Arbetsrapport 23, Sveriges Riksbank.

Bryan, M. F. \& Cecchetti, S. G. (1994). Measuring Core Inflation, in N. G. Mankiw (ed.), Monetary Policy, The University of Chicago Press, pp. $195-215$.

Bryan, M. F., Cecchetti, S. G. \& WigginsII, R. L. (1997). Efficient Inflation Estimtion, Working Paper 6183, NBER.

Diewert, W. E. (1995). On the Stoachstic Approach to Index Numbers, Discussion Paper 95-31, Department of Economics, University of British Columbia.

Doornik, J. A. \& Hendry, D. F. (1998). PcFiml 9.10 A Module for Econometric Modelling of Dynamic Systems.

Dow, J. P. (1994). Measuring Inflation Using Multiple Price Indexes, mimeo, Department of Economics, University of California Riverside. 
European Central Bank (2001). Measures of Underlying Inflation in the Euro Area, Monthly Bulletin, July, pp. 49 - 59.

Fase, M. \& Folkertsma, C. (1997). Measuring Inflation: An Attempt to Operationalize Carl Menger's Concept of the Inner Value of Money, Staff Reports, De Nederlandsche Bank.

Friedman, M. (1977). Nobel Lecture: Inflation and Unemploymant, Journal of Political Economy 85: $451-472$.

Gartner, C. \& Wehinger, G. D. (1998). Core Inflation in Selected European Union Countries, Working Paper 33, Oesterreichische Nationalbank.

MacKinnon, J. (1991). Critical Values for Co-integration Tests, in R. Engle \& C. Granger (eds), Long-Run Economic Relationships, Oxford University Press, Washington, pp. $267-67$.

Osterwald-Lenum, M. (1992). A Note with Quantiles of the Asymptotic Distribution of the LM Cointegration Rank Test Statistics, Oxford Bulletion of Economics and Statistics 54: $461-472$.

Quah, D. \& Vahey, S. P. (1995). Measuring Core Inflation, The Economic Journal 105(September): $1130-1144$.

Shapiro, M. \& Watson, M. (1988). Sources of Business Cycle Fluctuations, in S. Fisher (ed.), NBER Macroeconomic Annual, MIT Press, Cambridge, Mass., pp. 111 - 148.

Stock, J. \& Watson, M. (1991). A Probability Model of the Coincident Economic Indicator, in K. Lahiri \& G. Moore (eds), Leading Economic Indicators New Approaches and Forecasting Records, Cambridge University Press, pp. 63 - 89.

Vega, J.-L. \& Wynne, M. A. (2001). An Evaluation of Some Measures of Core Inflation for the Euro Area, Working Paper 53, European Central Bank. 
Wehinger, G. D. (2000). Causes of Inflation in Europe, the United States and Japan: Some Lessons for Maintaining Price Stability in the EMU from a Structural VAR Approach, Empirica 27: 83 - 107.

Wynne, M. (1999). Core Inflation: A Review of Some Conceptual Issues, Working Paper 5, European Central Bank. 


\section{A Tables Appendix}

Table 1: Unit Root Tests ${ }^{+}$

\begin{tabular}{|c|c|c|c|c|c|c|c|}
\hline \multirow{2}{*}{ Variable } & \multirow{2}{*}{ Notation } & \multicolumn{2}{|c|}{ ADF Test } & \multicolumn{2}{|c|}{ PP Test } & \multirow{2}{*}{$\begin{array}{c}5 \text { Percent } \\
\text { Crit. Val. }{ }^{++}\end{array}$} & \multirow{2}{*}{ Decision } \\
\hline & & Setup $^{+}$ & Statistic & Setup $^{++}$ & Statistic & & \\
\hline$\overline{l e} \log (G D P)$ & $y$ & $\overline{c c, t, 1}$ & -1.74 & $\overline{c, t, 3}$ & -1.66 & -3.48 & $\overline{I I(1)}$ \\
\hline$\triangle \log (G D P)$ & $\triangle y$ & $\mathrm{c}$ & $-5.10^{*}$ & $\mathrm{c}, 3$ & $-5.18^{*}$ & -2.90 & \\
\hline $\begin{array}{c}\log (P) \\
\triangle \log (P)\end{array}$ & $\begin{array}{c}p \\
\triangle p\end{array}$ & $\begin{array}{c}\mathrm{c}, \mathrm{t}, 1,2, \mathrm{~s} \\
\mathrm{c}, \mathrm{s}\end{array}$ & $\begin{array}{c}-0.88 \\
-4.09 *\end{array}$ & $\begin{array}{c}\mathrm{c}, \mathrm{t}, 3 \\
\mathrm{c}, 3\end{array}$ & $\begin{array}{c}-0.05 \\
-5.59^{*}\end{array}$ & $\begin{array}{l}-3.48 \\
-2.90\end{array}$ & $\mathrm{I}(1)$ \\
\hline
\end{tabular}

* indicates significance at the five percent level

+ sample period: 1985(3) - 2000(4)

${ }^{++}$c: constant, t: trend, s: seasonal dummies, the integers indicate the lags of differenced dependent variables included in the regression (ADF test) and the truncation lag (PP test)

+++ MacKinnon (1991) critical values

Table 2: Johansen Cointegration Test ${ }^{+}$for $x_{t}=\left(y_{t}, p_{t}\right)$

\begin{tabular}{|c|c|c|}
\hline $\begin{array}{c}H_{0} \\
r=0\end{array}$ & $\begin{array}{c}\text { LR Trace } \\
\text { Statistic }\end{array}$ & $\begin{array}{c}\text { Critical Values }^{++} \\
5 \%\end{array}$ \\
\hline \hline 0 & 11.96 & 15.40 \\
1 & 0.72 & 3.80 \\
\hline
\end{tabular}

* indicates significance at the five percent level

+ The test was specified with an unrestricted constant and centered seasonal dummies. Sample period: 1985(3) - 2000(4)

++ Osterwald-Lenum (1992) critical values

Table 3: Information Criteria ${ }^{+}$

\begin{tabular}{|c|l|l|l|}
\hline Lag Order(k) & AIC & SC & HQ \\
\hline \hline 1 & -22.59 & -22.46 & -22.54 \\
2 & -22.81 & $-22.54^{*}$ & $-22.70^{*}$ \\
3 & -22.79 & -22.39 & -22.64 \\
4 & $-22.89^{*}$ & -22.35 & -22.67 \\
5 & -22.83 & -22.15 & -22.56 \\
6 & -22.73 & -21.90 & -22.40 \\
\hline
\end{tabular}

AIC: Akaike Information Criterion

SC: Schwarz Criterion

HQ: Hannan-Quinn Criterion

* indicates the minimum of the column

+ sample period: $1985(3)-2000(4)$ 
Table 4: Likelihood Ratio Test $(\mathrm{LR})^{+}$

\begin{tabular}{|c|c|c|}
\hline$H_{0}$ vs. $H_{1}$ & LR-Statistic & Probability \\
\hline \hline$k=6$ vs. $k=5$ & 0.32 & 0.98 \\
$k=5$ vs. $k=4$ & $18.41^{*}$ & 0.00 \\
$k=4$ vs. $k=3$ & $17.69^{*}$ & 0.00 \\
$k=3$ vs. $k=2$ & 4.14 & 0.38 \\
$k=2$ vs. $k=1$ & $11.31^{*}$ & 0.02 \\
\hline
\end{tabular}

* indicates significance at the five percent level

+ sample period: $1985(3)-2000(4)$

Table 5: Residual Analysis ${ }^{+}, \operatorname{VAR}(5)$

\begin{tabular}{|c|c|c|c|c|c|}
\hline \multirow{2}{*}{ Test } & \multicolumn{2}{|c|}{ Residuals of single equations } & \multicolumn{2}{|c|}{ Vector } \\
\cline { 2 - 6 } & d.f. & $\triangle y$ & $\triangle p$ & d.f. & $X$ \\
\hline \hline observ. & - & 62 & 62 & - & - \\
\hline AR(1-4) & $\mathrm{F}(4,44)$ & $\begin{array}{c}0.66 \\
(0.61)\end{array}$ & $\begin{array}{c}1.08 \\
(0.37)\end{array}$ & $\mathrm{F}(16,78)$ & $\begin{array}{c}1.26 \\
(0.24)\end{array}$ \\
\hline NORM & $\chi^{2}(2)$ & $\begin{array}{c}10.96^{*} \\
(0.00)\end{array}$ & $\begin{array}{c}1.59 \\
(0.45)\end{array}$ & $\chi^{2}(4)$ & $\begin{array}{c}12.47^{*} \\
(0.01)\end{array}$ \\
\hline ARCH(4) & $\mathrm{F}(4,40)$ & $\begin{array}{c}0.74 \\
(0.56)\end{array}$ & $\begin{array}{c}0.72 \\
(0.58)\end{array}$ & - & - \\
\hline Mis-spec & $\mathrm{F}(20,27)$ & $\begin{array}{c}0.71 \\
(0.78)\end{array}$ & $\begin{array}{c}1.51 \\
(0.15)\end{array}$ & $\mathrm{F}(60,75)$ & $\begin{array}{c}1.02 \\
(0.44)\end{array}$ \\
\hline
\end{tabular}

$\mathrm{AR}(1-4)$ tests significant autocorrelation of up to four lags, ARCH(4) tests for presence of autoregressive heteroscedasticity in the residuals up to order 4 ,

NORM is the Jarque-Bera test for normality, Mis-spec tests for general mis-specification.

* indicates significance at the five percent level

+ sample period: 1985(3) - 2000(4)

++ marginal level of significance in parentheses 


\section{B Data Appendix}
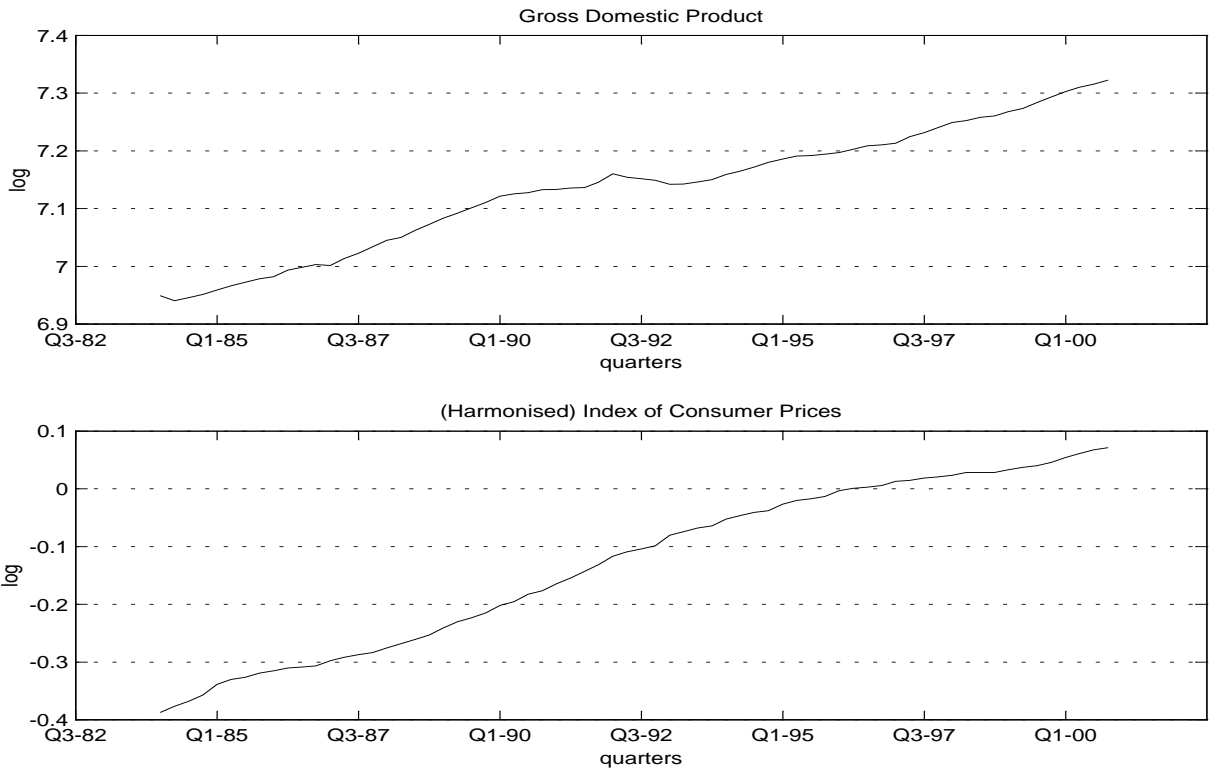

Figure 6: Data Graphics 
Table 6: Sources and periods of coverage of the real GDP

\begin{tabular}{|c|c|c|}
\hline Country & $\begin{array}{l}\text { Source I } \\
\text { Eurostat }\end{array}$ & $\begin{array}{l}\text { Source II } \\
\text { other }\end{array}$ \\
\hline Belgium & As from 1985 & $\begin{array}{l}\text { The data of the year } 1984 \text { is calculated on the basis of the } \\
\text { growth rates of } O E C D \text { data. }\end{array}$ \\
\hline Germany & & $\begin{array}{l}\text { The data has been supplied by the } D I W \text {. For the period } \\
\text { before } 1989 \text { the data for unified Germany is calculated on } \\
\text { the basis of the growth rates of West Germany. }\end{array}$ \\
\hline Spain & All & \\
\hline France & As from 1990 & $\begin{array}{l}\text { For the period prior to } 1990 \text { the data is calculated on the } \\
\text { basis of growth rates of Eurostat data. }\end{array}$ \\
\hline Ireland & & $\begin{array}{l}\text { For the period before } 1990 \text { the data is calculated on the } \\
\text { basis of the extrapolated share of } 9 \text { EMU countries (EMU } \\
\text { except for Irland and Luxembourg). As from } 1990 \text { calcula- } \\
\text { tions of the } D I W \text { on the basis of indicators and the yearly } \\
\text { GDP data of the } O E C D \text { are used. }\end{array}$ \\
\hline Italy & All & \\
\hline Luxembourg & & $\begin{array}{l}\text { For the period prior to } 1990 \text { the data is calculated on the } \\
\text { basis of the extrapolated share of } 9 E M U \text { countries (EMU } \\
\text { except for Irland and Luxembourg). As from } 1990 \text { calcula- } \\
\text { tions of the } D I W \text { on the basis of indicators and the yearly } \\
\text { GDP data of the } O E C D \text { are used. }\end{array}$ \\
\hline Netherlands & As from 1990 & $\begin{array}{l}\text { For the period before } 1990 \text { the data is calculated on the } \\
\text { basis of the growth rates of Eurostat data. }\end{array}$ \\
\hline Austria & As from 1990 & $\begin{array}{l}\text { For the period prior to } 1990 \text { the data is calculated on the } \\
\text { basis of the growth rates of Eurostat data. }\end{array}$ \\
\hline Portugal & As from 1988 & $\begin{array}{l}\text { For the period before } 1988 \text { data is calculated on the basis } \\
\text { of growth rates of International Monetary Fund data. }\end{array}$ \\
\hline Finland & All & \\
\hline
\end{tabular}




\section{CFS Working Paper Series:}

\begin{tabular}{|c|c|c|}
\hline No. & Author(s) & Title \\
\hline 2001/01 & Stefanie Franzke & $\begin{array}{l}\text { Underpricing of Venture-Backed and Non } \\
\text { Venture-Backed IPOs: Germany's Neuer Markt }\end{array}$ \\
\hline $2001 / 02$ & Roland Beck & $\begin{array}{l}\text { Do Country Fundamentals Explain Emerging } \\
\text { Market Bond Spreads? }\end{array}$ \\
\hline $2001 / 03$ & $\begin{array}{l}\text { Markus Kern } \\
\text { Bernd Rudolph }\end{array}$ & $\begin{array}{l}\text { Comparative Analysis of Alternative Credit } \\
\text { Risk Models - An Application on German } \\
\text { Middle Market Loan Portfolios - }\end{array}$ \\
\hline $2001 / 04$ & $\begin{array}{l}\text { Antje Brunner } \\
\text { Jan Pieter Krahnen }\end{array}$ & $\begin{array}{l}\text { Multiple Lenders and Corporate Distress: } \\
\text { Evidence on Debt Restructuring }\end{array}$ \\
\hline $2001 / 05$ & $\begin{array}{l}\text { Ralf Ewert } \\
\text { Andrea Szczesny }\end{array}$ & $\begin{array}{l}\text { Countdown for the New Basle Capital Accord. } \\
\text { Are German Banks Ready for the Internal } \\
\text { Ratings-Based Approach? }\end{array}$ \\
\hline 2001/06 & Bernd Kaltenhäuser & $\begin{array}{l}\text { Explaining the Dollar-Euro Rate: Do Stock } \\
\text { Market Returns Matter? }\end{array}$ \\
\hline $2001 / 07$ & $\begin{array}{l}\text { Guenter Beck } \\
\text { Axel A. Weber }\end{array}$ & $\begin{array}{l}\text { How wide are European borders? } \\
- \text { New Evidence on the Integration Effects of } \\
\text { Monetary Unions - }\end{array}$ \\
\hline 2001/08 & $\begin{array}{l}\text { Yunus Aksoy } \\
\text { Tomasz Piskorski }\end{array}$ & Domestic Money and US Output and Inflation \\
\hline 2001/09 & Elke Hahn & $\begin{array}{l}\text { Core Inflation in the Euro Area: Evidence from } \\
\text { the Structural VAR Approach }\end{array}$ \\
\hline
\end{tabular}

Copies of working papers are available at the Center for Financial Studies or can be downloaded (http://www.ifk-cfs.de). 